\title{
JUDGMENT IN ANAESTHESIA FOR THE EMERGENCY OPERATION
}

\author{
LEONARD C. JENKINS, B.A., M.D., C.M., F.R.C.P.(C), * \\ AND Horace B. Graves, B.A., M.D., C.M. $\dagger$
}

\begin{abstract}
Happy is the man possessing
The superior holy blessing of Judgment-

Accurate, refined and chaste.
\end{abstract}

Aristophanes (446 B.c.)

Clinical Situations arise wherein the anaesthetist may recommend postponement of an emergency operation. The decision as to whether or not to induce anaesthesia in patients under these circumstances is sometimes difficult. Are these hesitations justified? What are base lines of limitations to risk? Where can the line be drawn and surgery justifiably postponed?

"In anaesthesia, as in all branches of medicine, a variety of factors must be weighed before a final decision is reached. The process of balancing the favorable and the unfavorable, the likely and the unlikely can be called judgment."'

In most instances, surgeons and anaesthetists recognize the need for mutual respect and confidence. Occasionally, however, a variety of pressures combine to cloud the judgment of one or the other. At this time a patient's welfare can be jeopardized. There are clinical situations in which a hasty decision to "get on" with the anaesthesia and the operation may lead to preventable and sometimes fatal, complications. These are outlined in Table l. Proper judgment in anaesthesia under these circumstances is essential.

TABLE I

Situations Requiring JUdgment in Anaesthesia for THE EMERGENCY Operation

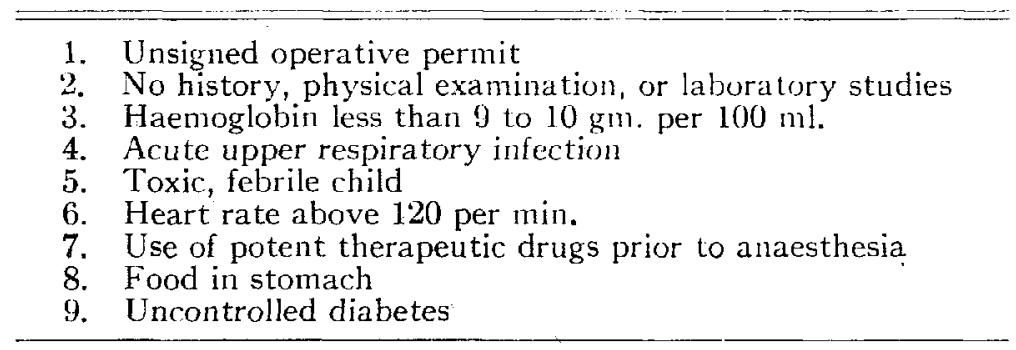

\section{The Unsigned Operàtive Permit}

The administration of anaesthesia to a patient: for whom there is nc anaesthetic and operative permit is legally wrong. The surgeon and the al

*Department of Anaesthesiology, Vancouver General Hospital, and the University of British Columbia, Vancouver, British Columbia.

†Director of Anaesthesiology, Vancouver General Hospital, and Clinical Associate Professor of Surgery, Medical Faculty, University of British Columbia.

Can. Anaes. Soc. J., vol. 9, no. 3, May, 1962 
tist are not liable for each other's acts and omissions. ${ }^{2}$ Although there is no unanimity in the laws of the various provinces, legal action against physicians appears to be increasing. No individual should be anaesthetized unless local legal requirements have been met. All physicians must be cognizant of these local laws. On the other hand, one cannot stand on ceremony in the face of threat to a patient's life. To refuse anaesthesia under these circumstances because proper permission has not been obtainable is unthinkable. An anaesthetist and surgeon can protect themselves in part by recording on the patient's chart reasons for their decision, especially if this decision appears to conflict with the law. It is inconceivable that, if anaesthesia and operation are deemed necessary to preserve life and if this judgment is duly recorded, a court would rule against a physician because of a failure to await signed operative permission. The record is of paramount importance, however.

\section{Absence of History, Physical Examination, or Laboratory Studies on the Patient's Chart}

Omission of these data suggests that the appraisal of the patient's condition has been inadequate. There is no substitute for a complete preoperative examination. While the extent of the work-up may vary according to the reasons for which the patient is being operated upon, minimal demands for any patient being anaesthetized are a recorded history and physical examination of the circulatory, respiratory, and central nervous systems. Experiences with previous anaesthetics, allergic history, and previous and present medications should also be recorded. Minimal laboratory studies should include urinalysis and estimation of haemoglobin. Time must be provided, regardless of personal pressures, with almost no exception for some sort of an appraisal of every patient. Some hospitals will not permit a patient to leave the ward for the operating theatre until the history and physical examination have been recorded on the chart.

\section{The Surgical Patient with Anaemia}

Is there a certain level of haemoglobin below which operation is contraindicated? Many competent authorities suggest 9 to $10 \mathrm{gm}$. per $100 \mathrm{ml}$. blood as the dividing line, recognizing that any given figure represents an arbitrary decision. ${ }^{1}$ The underlying reasons for knowledge of the haemoglobin concentration are more important than a rule of thumb for the rejection of patients for operation. For instance, the primary contribution of haemoglobin to the body is its capacity to carry oxygen. Reduction in the amount of haemoglobin may jeopardize tissue oxygenation. While this may not become of concern in most patients with low haemoglobin who are anaesthetized, it may be of considerable significance to those experiencing respiratory obstruction, hypoxia, or haemorrhage during operation. There is evidence that in severe anaemia, particularly if chronic, the heart is abnormal. Anginal symptoms suggesting myocardial ischaemia have been described and electrocardiographic changes peculiar to anaemia are recognized. Heart rate is often increased, blood volume may be diminished in chronic 
anaemia (and certainly is in the acute form), right auricular pressure may be elevated, and cardiac output is commonly increased. Fatty infiltration of myocardial muscle has been noted. Patients with such severe chronic anaemia withstand transfusion badly, occasionally experiencing fatal pulmonary oedema. Hypotension, tachycardia, delayed awakening from general anaesthesia, and a slower postoperative convalescence are common consequences of haemorrhage in the already anaemic subject. Dundee ${ }^{3}$ has demonstrated prolongation of thiopental anaesthesia in patients with 9 to $11 \mathrm{gm}$. $\mathrm{Hbg} . / 100 \mathrm{ml}$. blood. This may represent less combination of thiopental with red blood cells and hence less inactivation of the anaesthetic, or it might indicate an hypoxic effect on hepatic detoxification mechanisms, delaying the destruction of the drug. Also, because these patients may have an associated hypovolaemia, the "depth" of anaesthesia produced by thiopental, since it depends on the total volume in which the drug is distributed, ${ }^{4}$ may be profound. An overdose may easily be given.

It should be apparent that a plausible case can be made for avoiding anaesthesia and operation, whenever possible, until an anaemia, acute or chronic, has been corrected. For an average adult, 500 c.c. of blood transfused usually raises the haemoglobin content of circulating blood by 10 per cent $(1.5 \mathrm{gm}$. of haemoglobin per 100 c.c.) and the erythrocyte count 500,000 per cubic millimetre. ${ }^{5}$ Perhaps packed red blood cells should be used more frequently than they are at present, in the emergency preparation for surgery of a patient with chronic anaemia.

\section{Patients with Acute Upper Respiratori Tract Infection}

For decades tradition has dictated postponement of anaesthesia in the face of an acute upper respiratory tract infection. The principal reason was the anticipation of "ether pneumonia." An irritated respiratory tracts pours out excessive secretions. These can prove troublesome during general anaesthesia and may increase the incidence of atelectasis during or following anaesthesia. Avoidance of general anaesthesia or the use of spinal or peridural anaesthetic methods does not remove the threat of pulmonary complications. Studies of comparable groups of patients given general and spinal anaesthesia for upper abdominal operations revealed no difference in the incidence of postoperative pulmonary morbidity. ${ }^{6}$ Presumably body resistance is lowered by the stress of operation, chilling can occur, and exposure to the bacterial flora of operating theatre personnel is similar, regardless of the technique of anaesthesia-a point that is often not realized.

The advent of antibiotics appears to diminish concern over acute respiratory infections in patients scheduled for operation. Despite the fact that antibiotics are not specific against the acute "colds," patients are commonly given an "antibiotic cover" and operation then scheduled accordingly. This tends to reduce anxiety regarding pulmonary sequelae and perhaps greater chances are taken. Although such a concept is not sound, the current threat of antibioticresistant staphylococcal pulmonary infections makes it even less sensible. Furthermore, a "cold" may be the prodrome of a more severe illness, such as influenza, nephritis, poliomyelitis, or the exanthems. Postoperative coughing will 
of ten produce severe tension on an abdominal wound, leading to evisceration of bowel and the dreaded sequelae that follow. A return to the more conservative attitude of the past is indicated. If feasible, postponement is advisable, until the upper respiratory tract infection is controlled. Anaesthetic vapours, and especially intubation of the vocal cords will initiate larygneal oedema and severe upper respiratory tract obstruction in a patient with upper respiratory infection.

\section{The Toxic, Febrile Child}

To rush a dehydrated, febrile infant or child from the admitting office to the operating room is unwise unless immediate surgical intervention is mandatory. Fortunately, such speed is seldom indicated. The principal deterrent to hurried operation is the fact that administration of most inhalational anaesthetics to such patients is often followed by convulsions. Heat retention, hypercarbia, and the effects of the anaesthetics have all been implicated. The underlying mechanisms have not been convincingly defined but it is a fact demonstrated all too of ten that the febrile, dehydrated infant or child tolerates inhalational anaesthetics poorly. Adequate preparatory parenteral fluid therapy coupled with efforts to reduce body temperature will materially reduce this danger. During the latter part of the preparatory period, preanaesthetic medication with a barbiturate can be exerting its sedative effect. Doses of atropine or scopolamine should be-reduced to lessen the risk of heat retention.

While convulsions may develop in an adult under similar circumstances, they are less likely to occur than in the younger age group.

\section{Patients with Preoperative Tachycardia}

An unexplained or unexpected elevation of pulse rate immediately prior to the induction of anaesthesia calls for considerable skill in interpretation. If an arbitrary rate must be selected at or above which we should become concerned, 120 per minute may be chosen.

Has an elevated pulse rate been a feature of the patient's course prior to hospitalization? This is likely to appear concomitantly with anaemia, thyrotoxicosis, fever, and in certain forms of heart disease. In the presence of such entities, one has to make the decision as to whether tachycardia indicates a sufficiently inadequate circulatory reserve to warrant further therapy. Transfusion for the anaemic, a better control of the thyroid, additional digitalis for the cardiac may be indicated. Affirmative answers to these questions require postponement of operation.

If, on the other hand, the tachycardia represents a new development, additional possibilities are suggested. It may reflect tension, fear, or anxiety. If so, induction of general anaesthesia by a slow intravenous injection of 50 to $100 \mathrm{mg}$. of thiopental, thereby producing a state of drowsiness, may suffice to produce a slowing of the heart rate. Anaesthesia and operation may then be continued as planned. 
The tachycardia may represent a response to certain drugs used for preanaesthetic medication. Meperedine, ${ }^{7}$ atropine, and chlorpromazine ${ }^{8}$ have thus been implicated. Such an elevated heart rate may be associated with concurrent hypotension, or a significant decrease in blood pressure may follow induction of general anaesthesia.

The decision to proceed with anaesthesia in the face of tachycardia is difficult. It seems best to postpone the surgical procedure and to restudy the patient, and if nothing is found to explain the tachycardia, to reschedule the operation using a different type of preanaesthetic sedation.

\section{Use of Potent Therapeutic Drugs Prior to Anaesthesta}

Some of the drugs used in modern therapeutics can affect the course of anaesthesia unfavorably. It is essential, therefore, that a careful history of all medication taken should be part of the preanaesthetic evaluation. Drugs of chief concern are the adrenal corticoids, such as cortisone and antihypertensive or tranquillizing drugs such as reserpine or chlorpromazine. Knowledge that a patient has been receiving these compounds may enable the anaesthetist to avoid serious arterial hypotension.

(a) Cortisone. Treatment with cortisone for 5 days or more is associated with distinct functional depression and histologic signs of atrophy of the adrenal cortex. In response to tissue injury, as with surgery, such a patient's adrenal cortex cannot produce a sufficient amount of corticoid to meet the demand. Hypotension is usually the chief manifestation of this adrenal insufficiency. Patients who have received cortisone must therefore be continued on the drug and receive increased amounts during anaesthesia and surgery.

The time required for return of húman adrenal cortical function to normal after cessation of cortisone therapy is not known. Probably the intensity and duration of treatment are factors. Although perhaps not applicable in an emergency situation, theoretically, if one is in doubt about adrenal cortical function, injection of ACTH and estimation of the urinary steroid excretion and the eosinophil response will indicate the extent of adrenal cortical suppression. Some reports ${ }^{9}$ have indicated that patients with a history of having received cortisone within two years of a proposed operation should be given the drug again as a prophylactic measure. If cortisone is used under these circumstances, doses are in the range of $100 \mathrm{mg}$. intramuscularly b.i.d. 24 hours preoperatively and 1 to 2 hours before operation, and $100 \mathrm{mg}$. of hydrocortisone sodium succinate intravenously during the surgery as indicated.

(b) Reserpine. Arterial hypotension has been reported following the administration of general anaesthesia to hypertensive patients who have been receiving Rauwolfia or reserpine. Some workers believe that this untoward effect is related to increased vagal activity. The hypotension noted will frequently respond to a vagal blocking drug, such as atropine, given intravenously. How frequently this hypotension occurs is not known, nor has it been definitely related to dosage or duration of therapy. These drugs appear to exert a pharmacologic effect for 10 to 14 days after administration. 
(c) Chlorpromazine. Arterial hypotension has been observed more frequently during anaesthesia in patients receiving chlorpromazine. The duration of action of this compound is brief. There is no problem within 8 hours of interruption of therapy.

In all probability, additional therapeutic agents will be developed which may pose a threat to patients during anaesthesia and operation. The habit of asking about all medications is therefore essential. An anaesthetist is likewise obligated to keep abreast of the possibility of harm from new methods of treatment.

\section{Presence of Food in the Stomach}

This is of concern to patient, surgeon, and anaesthetist alike. Anaesthesia may initiate vomiting and may be associated with a loss of reflexes normally preventing the entry of foreign material into the respiratory tract. Undigested solid food may lodge in the glottis or trachea causing complete respiratory tract obstruction. Liquid material may be aspirated into the air passages, leading to chemical irritation, bronchospasm, and cyanosis. If these complications are overcome, a chemical pneumonitis may subsequently develop. ${ }^{10}$

There are circumstances under which an emergency operation is planned, yet the presence of food or fluid in the stomach poses a threat to the patient. For instance, emergency Caesarean section or, more commonly, normal vaginal birth. Not uncommonly one is confronted with a patient who was injured shortly after eating. Gastric emptying is delayed, often for hours, by pain or fright. Another illustrative case is that of the patient with upper small bowel obstruction, bleeding gastric ulcer, or bleeding tendencies associated with blood loss in to the upper gastrointestinal tract. If these patients are unconscious or semiconscious, gastric contents can regurgitate into the pharynx and thence past the larynx in to the lungs without obvious vomiting. Respiratory obstruction from solid material is rarely of concern but a large volume of fluid may overwhelm the lungs, particularly if the anaesthetist is unaware of the regurgitation. Children may swallow large amounts of blood following tonsillectomy complicated by postoperative bleeding. Any child to be anaesthetized for suture of a bleeding tonsillar fossa should be assumed to have blood in the stomach.

These situations may tax the judgment of an anaesthetist. Preferably 5 hours should elapse between ingestion of food or drink and operation. One should remember that narcotic drugs delay gastric emptying.

Various solutions may be formulated for this problem. When local anaesthesia can be used, as for example, injection of a local anaesthetic into a fracture site, or field block for an intra-abdominal operation, this is believed to be safest. Spinal or peridural anaesthesia offer certain advantages in that there is less depression of protective respiratory reflexes and stimulation of vomiting centres is minimal. Should the patient vomit under these conditions, he is less likely to aspirate material into the tracheo-bronchial tree. Merely because the patient is conscious, however, is no assurance that he cannot vomit and aspirate gastric contents. Copious active or regurgitant vomiting can be so overwhelming as to make aspiration inevitable. 
When general anaesthesia appears necessary, there are two approaches. The first is to clear the stomach of its contents and the second is to protect the lower airway so that vomited material cannot gain entrance to it. The stomach can be partially emptied by several methods such as inducing vomiting reflexly by stimulation of the posterior pharynx, or by passage of a large-bore Levin or gastric tube. While neither of these tubes permits removal of solid material, its passage or attempted passage of ten leads to the more effective reflex vomiting. The only sure way of clearing the stomach is to induce vomiting.

Where it is impractical or impossible to empty the stomach, a cuffed endotracheal tube should be inserted into the trachea of the patient. In some instances, for example, peritonsillar abscess with trismus, this is best done while the patient is still conscious. The cuff is then inflated. This can be accomplished with the topical application of 4 per cent Xylocaine into the nasopharynx, oropharynx, and larynx and then placing of the tube either blindly or under direct vision. Even this procedure is not completely safe, however, so suction apparatus (tonsillar type) should be connected and at hand during topical anaesthetization and insertion of the tube. More commonly the patient's co-operation cannot be secured, and the rapid intubation of the trachea with the aid of a combination of thiopentone, succinycholine, and moderate foot-down position ${ }^{11}$ is carried ou1 Although large-bore cuffed oesophageal tubes have been advocated to seal off the gastrointestinal tract from the respiratory tract, we have not been impressed with their efficacy. The anaesthetist's index of suspicion should not be lowered by a single episode of vomiting, since the stomach may not be emptied by this one effort.

Apomorphine is not advised as a mode of inducing vomiting, since its use may be followed by central nervous system depression.

\section{Uncontrolled Diabetes}

Diabetic patients may be affected by any disease but there are certain surgical conditions, such as atherosclerotic gangrene, cholecystitis, cholelithiasis, to which they are more prone than the average person. The present average mortality rate in surgery on diabetics is practically the same as the over-all average for the general population. However, the mortality rate from anaesthesia is significantly increased by fatal regurgitation or vomiting when oral hypertonic glucose solutions are given an hour or so preoperatively. Therefore, this practice is condemned. Moreover, the amount of glucose that can be administered in this way is limited. Glucose is better given intravenously, at this time. Remember, however, that intravenous 5 per cent glucose and water to which insulin has been added is not a safe procedure unless you follow that intravenously with 5 per cent glucose in water without insulin. The insulin acts for much longer than the glucose infused remains in the blood, leading to a tendency to hypoglycaemia, 2 to 4 hours after the end of the infusion of glucose and insulin. Myocardial and cerebral infarctions have occurred as a result of hypoglycaemia during anaesthesia.

Certainly diabetes is not a contraindication to any necessary operation. However, the surgical risk is increased in diabetics in the presence of poor 
regulation, obesity, cardiovascular disease, or atherosclerosis. Any diabetic patient who has borne the disease for a decade or more should be considered as afflicted with latent (if not overt) coronary, cerebral or renal, arterial atherosclerotic disease. Hypertension added to diabetes increases the prematurity and degree of atherosclerosis. The anaesthetic should be governed accordingly.

Elective operations must never be performed on patients with uncontrolled diabetes.

Anaesthesia for the emergency operation upon the diabetic whose inflammatory surgical disease has thrown him out of control presents a problem. Hyperglycaemia without acidosis is not a contraindication to immediate anaesthesia and surgery. However, if the plasma $\mathrm{CO}_{2}$ combining power is below $15 \mathrm{mEq} . / \mathrm{L}$. (35 vol.\%), the induction of anaesthesia is hazardous and should be postponed until the acidosis is treated. This can be accomplished in 24 hours or less in most cases by giving varying amounts of unmodified insulin and a standard $40 \mathrm{gm}$. glucose feeding by mouth or vein $\mathrm{q} 4 \mathrm{~h}$. Tests of urinary glucose and acetone at the end of each 4 -hour period (before the next feeding) are used to govern the next dose of insulin.

The primary dangers that a diabetic patient faces during anaesthesia and operation, then, are those of any atherosclerotic patient plus the hazards of acidosis and hypoglycaemia. Acidosis must be eliminated prior to operation and hypoglycaemia must not be allowed to develop.

\section{SUMMARY}

Clinical situations arise where the anaesthetist may recommend postponement of an emergency operation. This may occur when a patient presents for surgery with (1) unsigned operative permit; (2) no history, physical examination, or laboratory studies; (3) haemoglobin less than 9 to $10 \mathrm{gm} . ;$ (4) acute upper respiratory infection; (5) toxic, febrile child; (6) heart rate $120 / \mathrm{min}$. or more; (7) the taking of potent therapeutic drugs prior to anaesthesia; (8) food in stomach; or (9) uncontrolled diabetes. A hasty decision to proceed with anaesthesia and operation under these circumstances may lead to preventable and sometimes fatal complications. Thus, proper judgment in anaesthesia in these instances is essential. If the decision is made to postpone, it is not obstructionism on the part of the anaesthetist, but is rather an attempt as a physician to improve the practice of medicine.

\section{RÉSUMÉ}

Il - se présente des situations cliniques où l'anesthésiste peut suggérer de rèmettre une opération urgente. Parmi ces situations citons les suivantes: (1) si le consentement à l'opération n'est pas signé; (2) si, au dossier, il n'y a pas d'histoire du cas, de rapport d'examen physique ou de résultats d'analyses de laboratoire; (3) si l'hémoglobine est moins de 9 ou 10 grammes; (4) si le malade est porteur d'une infection aigue des voies respiratoires supérieures; (5) si un enfant fait une température élevée d'origine infectieuse; (6) si le rythme cardiaque, 
à la minute, est de 120 et plus; (7) si, juste avant l'anesthésie, le malade a reçu de fortes doses de médicaments; (8) si l'estomac du malade contient des aliments; (9) si le malade est porteur d'un diabète non contrôlé. Dans ces circonstances, une décision hâtive de commencer une anesthésie et une opération peut entraîner des complications parfois fatales, mais qu'on aurait pu prévenir. Ainsi, dans ces circonstances, il est essentiel, en anesthésie, d'avoir un bon jugement. Si l'on en vient à la décision de remettre une opération, que l'on ne considère pas ce fait comme de l'obstruction de la part de l'anesthésiste, mais plutôt comme un désir, en qualité de médecin, d'améliorer la pratique de la médecine.

\section{REFERENCES}

1. Oech, S. R., \& Dripps, R. D. Judgment in Anaesthesia. Surg. Clin. N.A., W. B. Saunders Co. (October, 1958). pp. 1205-1213.

2. Harland, J. H, \& Mewetr, A. W. The Legal Relationship between the Surgeon and the Anaesthetist. Canad. Anaesth. Soc. J. 6: 299-321 (1959).

3. DundeE, J. W. The Effect of Anemia on the Action of Thiopentone. J. Irish Med. Assoc. 31: 351-354 (1952).

4. Price, H. L.; Dundee, J. W.; \& Conner, E. H. Rates of Uptake and Release of Thiopental by Human Brain; Relation to Kinetics of Thiopental. Anaesthesia Anaesthesiology 19:171 (January, 1957).

5. Rehder, K., \& SELDon, T. H. Indications for the Use of Fluids and Blood before and during Operation. Canad. Anaesth. Soc. J. 6: 385-392 (1959).

6. Dripps, R. D., \& Deming, M. V. Postoperative Atelectasis and Pneumonia. Ann. Surg. 124: 94-110 (1946).

7. Eckenhoff, J. E., \& Helrich, M. A Study of Narcotics and Sedatires for Use in Preanaesthetic Medication J.A.M.A. 167: 415-422 (May 24, 1958).

8. Dripps, R. D.; Vandam, L. D.; Pierce, E. C.; Oech, S. R.; \& Llirie, A A. The Use of Chlorpromazine in Anaesthesia and Surgery. Ann. Surg. 142:774-778 (1955).

9. Bayliss, R. J. Personal communications.

10. Marseall, B. M., \& Gordon, R. A. Vomiting, Regurgitation and Aspiration in Anaesthesia. I. Canad. Anaesth. Soc. J. 5: 274 (1958)

11. Snow, R. G., \& NunN, J. F. Induction of Anaesthesia in the Foot-down Position for Patients with a Full Stomach. Brit. J. Anaesthesia $81: 493-497$ (1960). 